Article

\title{
Assessment of IMERG Precipitation Estimates over Europe
}

\author{
Andrés Navarro ${ }^{1, *} \mathbb{D}$, Eduardo García-Ortega ${ }^{1} \oplus$, Andrés Merino ${ }^{1}{ }^{\circledR}$, José Luis Sánchez ${ }^{1}$, \\ Christian Kummerow ${ }^{2}$ and Francisco J. Tapiador ${ }^{3}$ D \\ 1 Atmospheric Physics Group (GFA), Department of Applied Physics, Universidad de León, 24071 León, \\ Spain; eduardo.garcia@unileon.es (E.G.-O.); amers@unileon.es (A.M.); jl.sanchez@unileon.es (J.L.S.) \\ 2 Department of Atmospheric Science, Colorado State University, Fort Collins, CO 80523, USA; \\ kummerow@atmos.colostate.edu \\ 3 Earth and Space Sciences Group (ESS), Institute of Environmental Sciences (ICAM), University of Castilla-La \\ Mancha, 45071 Toledo, Spain; Francisco.Tapiador@uclm.es \\ * Correspondence: andres.navarro@unileon.es; Tel.: +34-987-293-133
}

Received: 8 October 2019; Accepted: 22 October 2019; Published: 23 October 2019

check for updates

\begin{abstract}
This paper evaluates Integrated Multi-Satellite Retrievals from GPM (IMERG-F) over Europe for the period 2014-2018 in order to evaluate application of the retrievals to hydrology. IMERG-F is compared with a large pan-European precipitation dataset built on rain gauge stations, i.e., the ENSEMBLES OBServation (E-OBS) gridded dataset. Although there is overall agreement in the spatial distribution of mean precipitation $\left(R^{2}=0.8\right)$, important discrepancies are revealed in mountainous regions, specifically the Alps, Pyrenees, west coast of the British Isles, Scandinavia, the Iberian and Italian peninsulas, and the Adriatic coastline. The results show that the strongest contributors to poor performance are pixels where IMERG-F has no gauges available for adjustment. If rain gauges are available, IMERG-F yields results similar to those of the surface observations, although the performance varies by region. However, even accounting for gauge adjustment, IMERG-F systematically underestimates precipitation in the Alps and Scandinavian mountains. Conversely, IMERG-F overestimates precipitation in the British Isles, Italian Peninsula, Adriatic coastline, and eastern European plains. Additionally, the research shows that gauge adjustment worsens the spatial gradient of precipitation because of the coarse resolution of Global Precipitation Climatology Centre data.
\end{abstract}

Keywords: precipitation; satellite observations; surface observations; IMERG; Europe

\section{Introduction}

Accurate estimation of precipitation is essential in weather prediction, climate change research, and hydrologic applications [1-3]. However, unlike pressure and temperature, precipitation fields can be spatially patchy and consequently extremely difficult to measure and predict [4]. Many efforts have been made to measure precipitation since the 18th century, but building a global, consistent, and continuous database of rainfall is still challenging [5].

Currently, there are three main methods to measure precipitation, rain gauges, weather radars and satellite sensors. Rain gauges provide in situ, high time-resolution precipitation measurements at a given site. In spite of being considered the standard of precipitation measurement, rain gauges are subject to many uncertainties. For example, they provide point estimates that may be not fully representative of an area, especially large and complex ones with few stations [6]. Given the rapid spatial decorrelation of precipitation, network density is a key issue for rain gauge networks [7]. From 
the point of view of both precision and accuracy, rain gauges also have multiple errors due to wind, precipitation type, and poor maintenance of secondary stations $[8,9]$.

Weather radars are also widely used to measure precipitation over land. Ground radars provide good quality observations at high spatial and temporal resolution [10]. Nevertheless, they are still inadequate for quantitative global precipitation monitoring because of reduced spatial coverage and uncertainties related to the Z-R relationship, range effects, beam-blocking, clutter, and calibration errors $[11,12]$. Where integrated gauge-radar products exist, they tend to provide the best spatially averaged precipitation estimates. An example is the European network, but this does not cover the entire continent.

Satellite-derived rainfall products emerged 40 years ago as a promising alternative to measure precipitation at global scale $[13,14]$. By providing a homogeneous view of most of the planet, satellite data are not as prone to uncertainties because of sometimes very diverse instrumentation. The first visible/IR (Infrared Radiation) sensors were soon complemented with passive microwave (PMW) instruments, because electromagnetic radiation at microwave frequencies is affected by precipitation-sized particles but not by cloud droplets [15]. However, these instruments are also prone to problems such as limited temporal sampling (which can be alleviated using a constellation) and inherent limitations over land (because soil emissivity masks the rainfall signal) [16]. Spaceborne radars such as the precipitation radar onboard TRMM (Tropical Rainfall Measurement Mission) and the dual-frequency precipitation radar (DPR) in the Global Precipitation Measurement Core Observatory (GPM-CO) offer more direct observations of precipitation, but there is no constellation of orbital radars. In its absence, a combination of multiple satellite sensors is the natural, transient solution to providing accurate rainfall measurements for applications. The TRMM Multi-satellite Precipitation Analysis (TMPA) [17], Global Satellite Map Product (GSMaP) [18], and Integrated Multi SatellitE Retrievals from GPM (IMERG) $[19,20]$ are examples of such an approach.

The GPM-IMERG can be considered the successor of the TMPA. Since its first release in 2014, several studies have been devoted to evaluation of the product and its comparison with alternatives. Recent work by Prakash et al. [21] suggested that IMERG exhibits major improvements relative to TMPA in terms of capturing monsoonal precipitation. Omranian et al. [22] focused on the ability of IMERG to reproduce hurricanes, and Khan and Maggioni [23] evaluated the performance of IMERG over oceans. At country scale, validation exercises have published for mainland China [24], Saudi Arabia [25], Brazil [26], Cyprus [27], the Netherlands [28], Germany [29], Austria [30] and Spain [31], among others. There has, however, been no full validation for Europe.

This paper evaluates how IMERG compares with gauge-derived, high-resolution precipitation products used in climatological research. The datasets and methods used are presented in Section 2. Section 3 evaluates the performance of IMERG, highlights the main areas of discrepancy, and examines the underlying reasons for disagreements. Section 4 summarizes the main conclusions.

\section{Data and Methodology}

\subsection{Study Area}

The study area spans within the latitudes of $25^{\circ} 00^{\prime} \mathrm{N}-71^{\circ} 00^{\prime} \mathrm{N}$ and longitudes of $25^{\circ} 00^{\prime} \mathrm{W}-45^{\circ} 00^{\prime} \mathrm{E}$, covering most of European continent (Figure 1). The geography of Europe is variable, with substantive differences between regions. The combination of plains, uplands, and mountain ranges provides a good representation of diverse topographical and climatological conditions to test the performance of IMERG. 
A

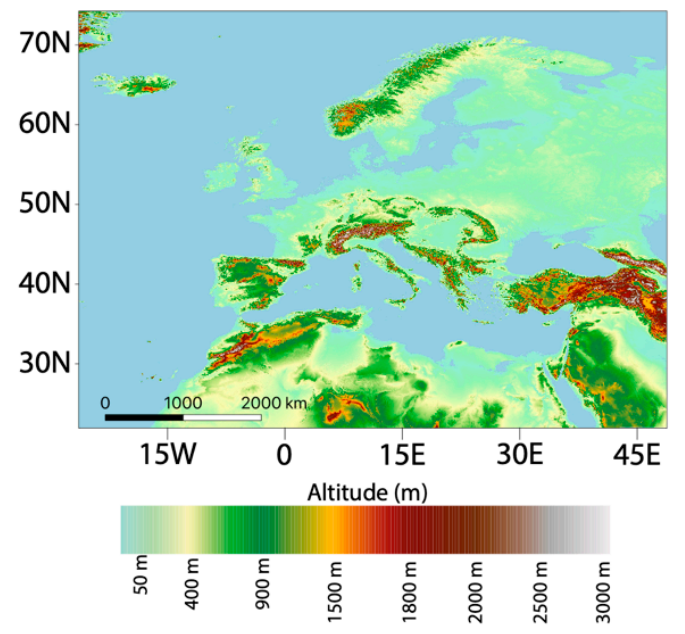

B

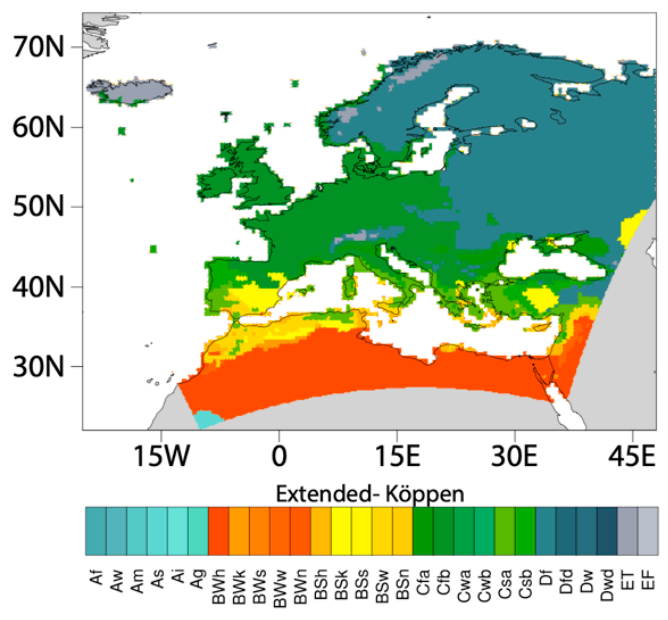

Figure 1. (A) Topographic map of Europe. (B) Extended Köppen climate classification map for the study area (cf. Tapiador et al. 2019 [32]).

Europe has five large climate regions according to the Köppen climate classification [33]. Southern Europe, Portugal, Spain, southeastern France, southwestern Italy, Greece, and Turkey are dominated by Mediterranean and semiarid climates (Csa, Csb, Bsh, and Bsk). These climates are characterized by dry-hot summers with precipitation totals less than $900 \mathrm{~mm} /$ year. The North Atlantic (northern Spain, France, northeastern Italy, the British Isles, Benelux, and western Germany) has a maritime climate $(\mathrm{Cfb})$. It typically lacks a dry season and precipitation comes in the form of rain during most of the year. Southern Scandinavia and Central and Eastern Europe have a humid continental climate (Dfa and $\mathrm{Dfb})$ that is typified by large seasonal temperature differences and year-round precipitation. Winter precipitation is frequently in the form of snow. Subpolar climates (Dfc) are mostly found in eastern Norway, Sweden, and Finland. They are defined by cold winters and short cool-to-mild summers, with annual precipitation usually less than $600 \mathrm{~mm}$. Alpine climates (ET) are restricted to the Alps, Iceland, and Scandinavian mountains.

\subsection{Datasets}

\subsubsection{Surface Reference Dataset: E-OBS}

E-OBS (ENSEMBLES OBServation) is a daily gridded observational dataset of precipitation, temperature and surface pressure in Europe $[34,35]$. Data are available on a $0.1^{\circ}$ regular grid and $0.22^{\circ}$ and $0.44^{\circ}$ rotated polar grids. The full version 19.0e dataset covers the period 1950-2018 and is freely available from https://copernicus.eu.

The station data are supplied by national meteorological services and other providers across Europe and the Middle East [36]. The data are quality-controlled by the national agencies and quality-checked by the ECA\&D (European Climate Assessment \& Dataset). The number of stations per pixel are irregularly distributed across the continent (Figure 2A), with relatively numerous stations across central Europe, Scandinavia, and the British Isles, and fewer toward the south and east of the domain shown in Figure 2. This issue is also seen in the Global Precipitation Climatology Centre (GPCC) data (Figure 2B). In fact, E-OBS is not fully independent of GPCC because both products share data from SYNOP (surface synoptic observations) stations. The added value of E-OBS is the inclusion of second-order stations such as those of subnational weather services. Thus, E-OBS has nearly 9000 stations, whereas GPCC only has $\sim 2770$ for the same domain and period. 
A

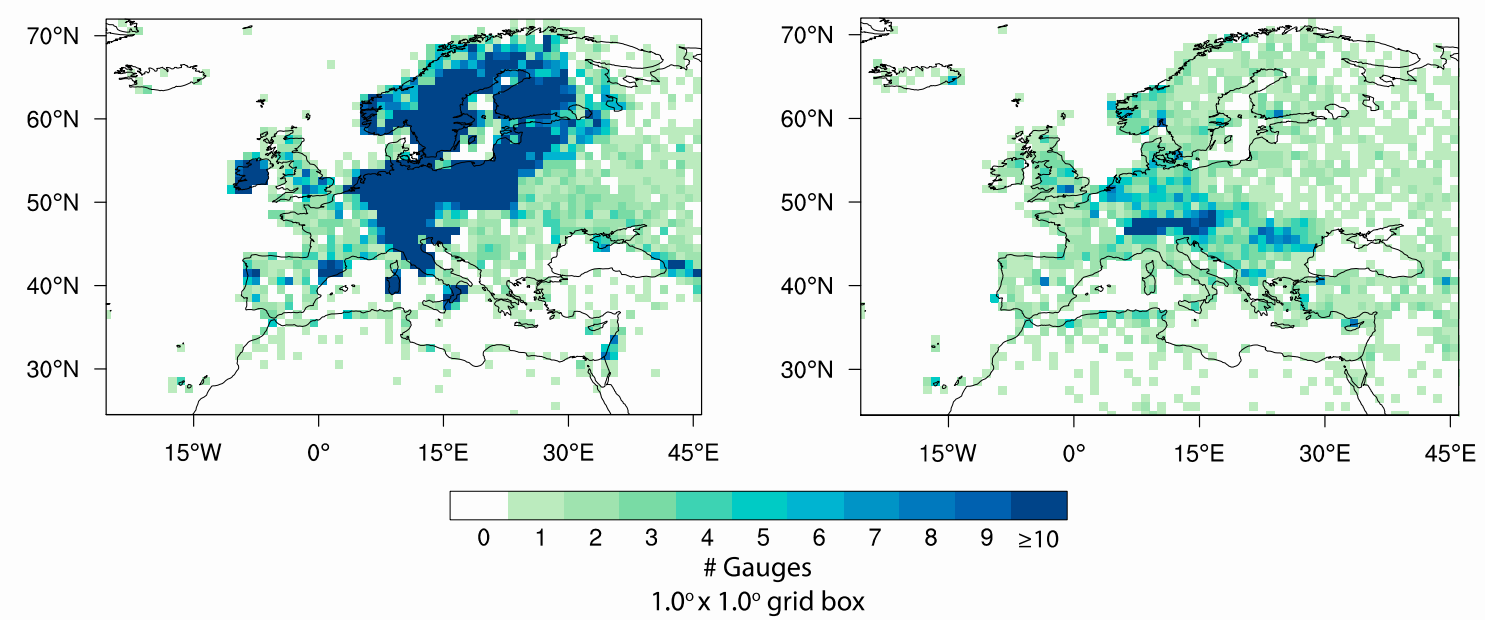

Figure 2. (A) Number of stations per grid box in ENSEMBLES OBServation (E-OBS) dataset v19. (B) Global Precipitation Climatology Centre (GPCC) meteorological stations per grid box. Integrated Multi-Satellite Retrievals from GPM (IMERG-F) uses GPCC for gauge adjustment. Results were set to a common grid $\left(1^{\circ} \times 1^{\circ}\right)$ for better comparison.

E-OBS has been widely used in peer review papers [37-39] and the validation of rainfall estimates from satellite data [40-42].

\subsubsection{GPCC}

The Global Precipitation Climatology Centre (GPCC) provides global (land-only) precipitation analyses at various temporal and spatial resolutions [43]. The database contains precipitation data from more than $\sim 80,000$ rain gauges around the globe. One of the gridded products released by GPCC is the GPCC-MP (GPCC Monitoring product v6; Figure 1B). It provides monthly precipitation data at $1.0^{\circ} \times 1.0^{\circ}$ in near real-time, and these data serve as bias correction for IMERG-F.

\subsubsection{IMERG}

IMERG Version 6B-Final (Integrated MultisatellitE Retrievals from GPM) is a precipitation dataset with $0.1^{\circ}$ spatial resolution and $30 \mathrm{~min}$ temporal resolution [44]. IMERG-F combines retrievals from PMW and microwave-calibrated IR to produce a quasi-global $\left(60^{\circ} \mathrm{S}-60^{\circ} \mathrm{N}\right)$ precipitation product based only on satellite data. Raw data are processed by the GPROF2017 algorithm [45] and then gridded and merged with IR data to provide global, homogeneous precipitation measurements. IMERG has three types of products, early (IMERG-E), late (IMERG-L), and final (IMERG-F). Although "early" and "late" products are available in quasi-near-real-time, the "final" version was released 2.5 months later. An advantage of IMERG-F is that it includes additional satellite data that may be delayed for any reason. The gridded data are available from mid-March 2014 to the present.

In the present study, two versions of the final precipitation estimate were used, IMERG-Cal and IMERG-Uncal. The former, in contrast to the latter, includes a monthly gauge dataset from GPCC in the bias correction algorithm. Unless otherwise indicated in the following sections, IMERG-F refers to the calibrated product of IMERG "final" for simplicity. Comparisons are therefore between the high-density rain gauge dataset from E-OBS and a satellite product that has been bias-adjusted to the lower-density gauge dataset from GPCC. 


\subsection{Metrics}

We assessed the performance of IMERG-F using both statistical and graphical methods. Standard metrics included descriptive analysis, the determination coefficient $\mathrm{R}^{2}$, and probability density functions (PDFs). Two more metrics were used, Cook's distance $D$ and the variogram $\gamma$.

Cook's distance is used in bivariate data analysis to find influential outliers [46]. In this paper, this method is used to identify pixels with greater discrepancies. It is defined as

$$
D_{i}=\frac{\sum_{j=1}^{j=n}\left(\hat{y}_{j}-\hat{y}_{j(i)}\right)^{2}}{p M S E},
$$

where $\hat{y}_{j}$ is the prediction from the full regression model for observation $j$, and $\hat{y}_{j(i)}$ is the prediction for observation $j$ from a refitted regression model in which observation $i$ has been omitted. MSE is the mean squared error and $p$ the number of fitted parameters. The larger $D$ is, the more influential the point $(D=0$ means a perfect score). We used the conventional threshold value $4 / n$ to identify outliers.

The variogram $\gamma$ is a geospatial analysis tool that measures the spatial variability of a field. Here, $\gamma$ is used as a metric to evaluate the similarity between the spatial structure of precipitation from E-OBS and IMERG-F. $\gamma$ is calculated from

$$
\gamma(h)=\frac{1}{2 n} \sum_{i j}\left(p_{i j}-p_{i j+h}\right)^{2}
$$

where $n$ is the number of pairs of grid points, $p_{i j}$ is precipitation at an individual grid point, and $p_{i j+h}$ is the precipitation distance $h$ from the point $i, j$, with the sum over all grid points.

\section{Results and Discussion}

\subsection{Comparisons}

\subsubsection{Annual and Seasonal Validation}

Annual and seasonal climatologies were compared against E-OBS data as the reference. Figure 3 shows overall agreement of the annual mean. IMERG correctly reproduces the rainiest western British Isles, western Scandinavia, northwestern Iberian Peninsula, the Alps, and east coast of the Adriatic sea, plus the driest areas in Europe (southeastern Iberian Peninsula, the Maghreb, and Syrian desert). The agreement is also shown by a scatter plot $\left(R^{2}=0.8\right)$. However, some discrepancies are worth pointing out. Firstly, IMERG-F overestimated annual mean precipitation in areas with precipitation rates $\sim 1.6 \mathrm{~mm} /$ day, especially on the Pontic-Caspian steppe, Oder River depression, and Pannonian Plain. Second, precipitation gradients in complex areas were poorly represented, e.g., the Italian Peninsula and British Isles. 


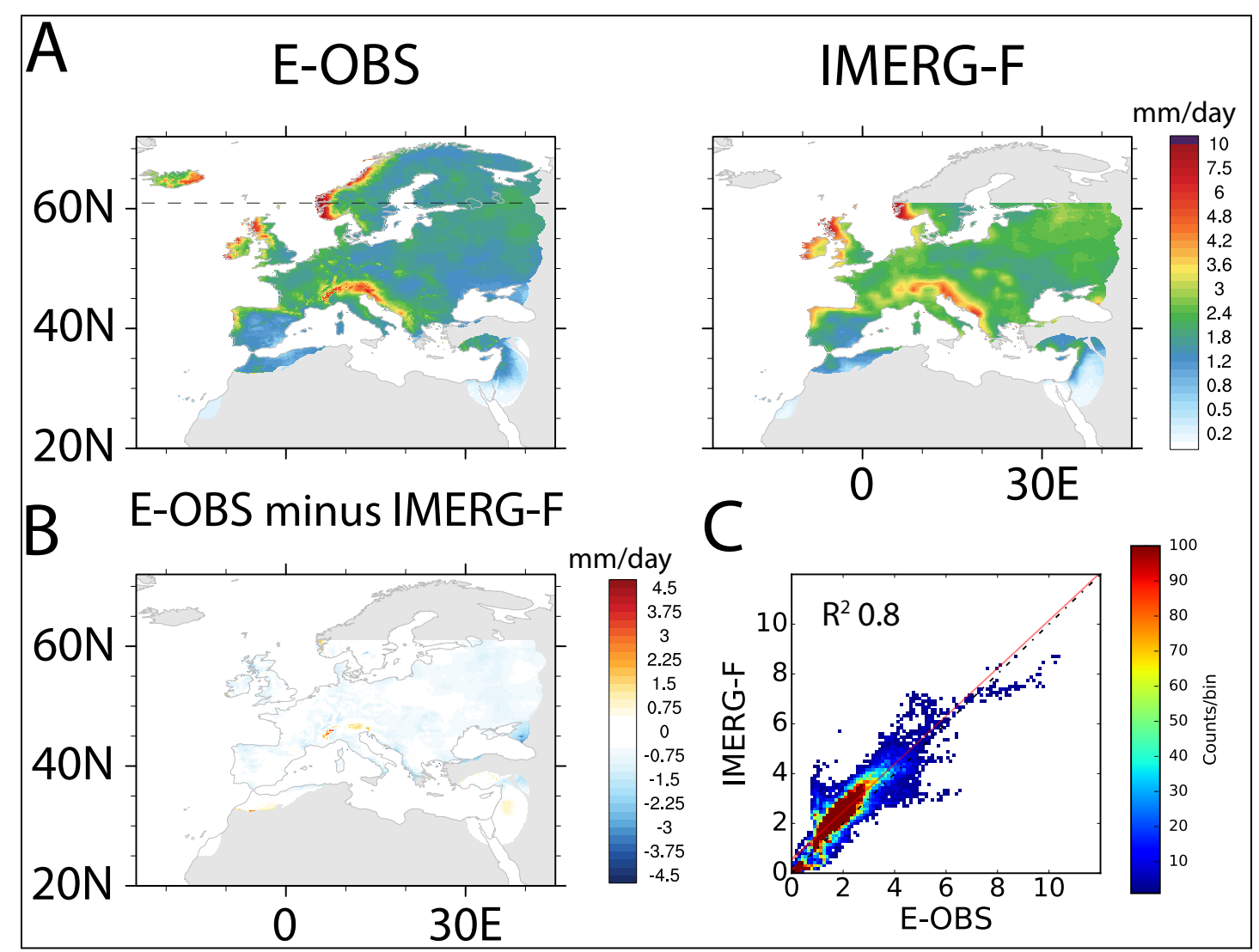

Figure 3. (A) Comparison of annual mean precipitation in the period June 2014-December 2018 from E-OBS (top left) and IMERG-F (top right). (B) Difference map between E-OBS and IMERG-F. (C) Scatter plot comparing annual mean precipitation at every grid point. The black dashed line is a 1:1 line and the red solid line represents linear fit.

Seasonal plots (Figure 4) show many of the features discussed for the annual mean. Generally, IMERG-F overestimated precipitation in most plain areas but underestimated in the Alps (all seasons). Indeed, this issue is clearer in humid continental climate regions (Dfb), especially in the cold season. A closer look at the Alps reveals greater underestimation during winter, but in summer when convective rain is more intense, there does not appear to be any major issue. Conversely, seasonal variability was well captured across the Iberian Peninsula, Greece, and countries of the Levantine Sea.

The scatter plots (Figure $4 B$ ) show the poorest correlation in the cold season (DJF). $\left(R^{2}=0.67\right)$ and the best in JJA $\left(R^{2}=0.89\right)$. Figure 5 compares the distribution of PDFs between E-OBS and IMERG-F. In terms of the annual mean, the precipitation distribution is similar to that of gauge observation. However, an underestimation of precipitation maxima and systematic overestimation of mean precipitation were common to all cases.

Seasonal variability was also well captured by IMERG-F except in the cold season (DJF). Here, IMERG-F had problems in correctly reproducing the distribution of precipitation, mainly caused by an excess of precipitation on the European plain (Figure 4A, first column). Conversely, IMERG-F gave the best result in summer, not only for the distribution of precipitation but also its mean (2.0-2.4 mm/day; Figure $4 \mathrm{~A}$, third column). 
A
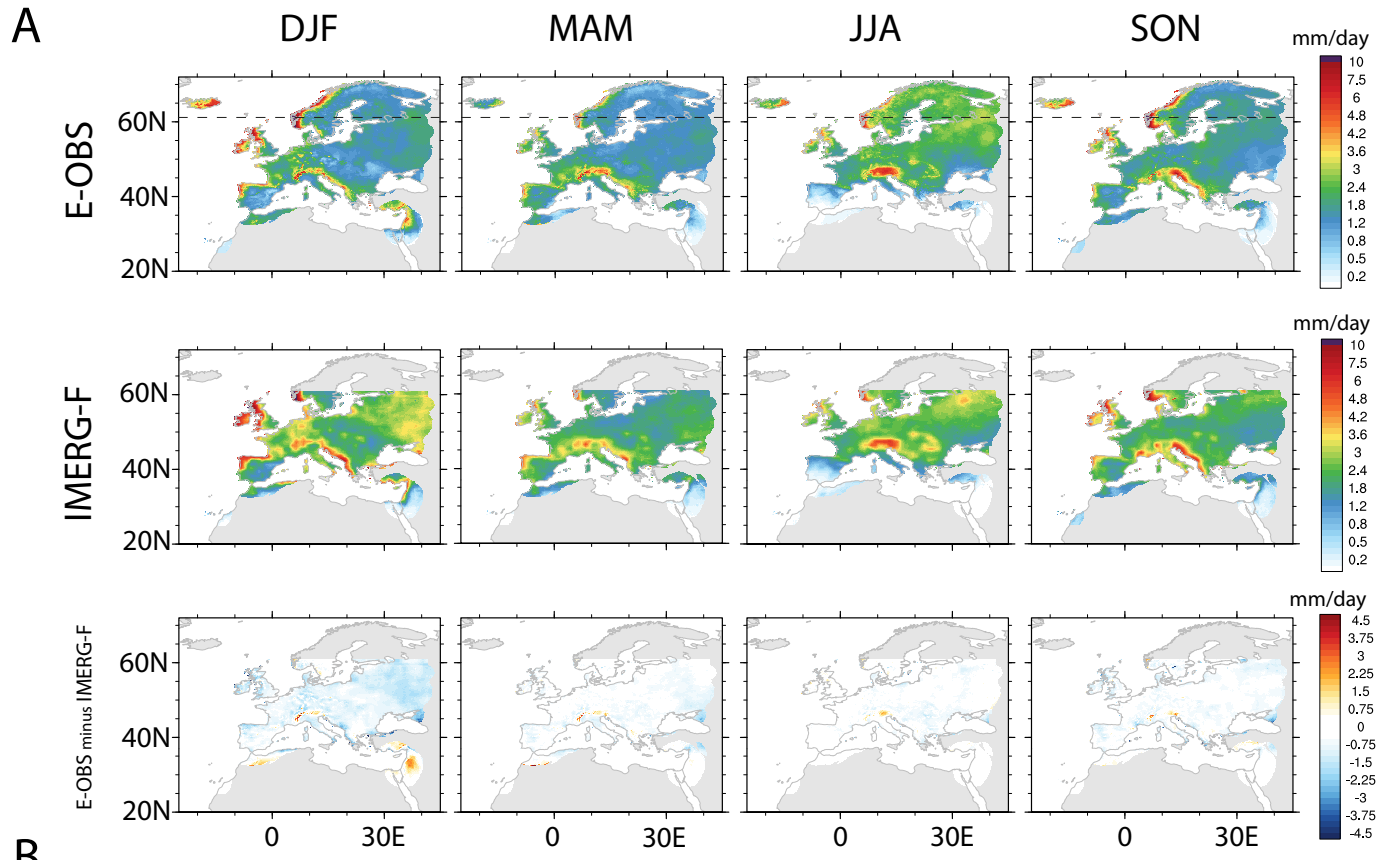

B
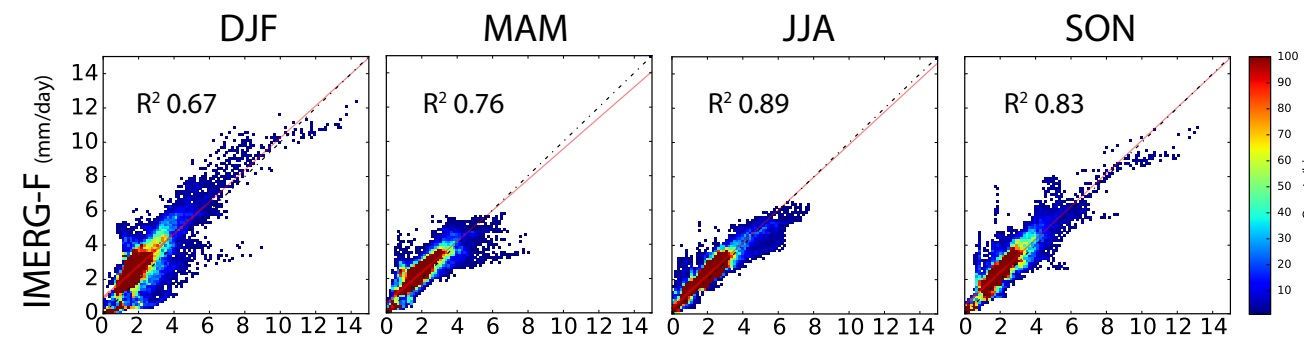

$\mathrm{E}-\mathrm{OBS}(\mathrm{mm} / \mathrm{day})$

$\mathrm{E}-\mathrm{OBS}(\mathrm{mm} / \mathrm{day})$

$\mathrm{E}-\mathrm{OBS}(\mathrm{mm} / \mathrm{day})$

$\mathrm{E}-\mathrm{OBS}(\mathrm{mm} / \mathrm{day})$

Figure 4. (A) Seasonal precipitation for E-OBS (first row) and IMERG-F (second row). Difference map between E-OBS and IMERG-F (third row). (B) Scatter plot comparing seasonal precipitation at every grid point. The black dashed line is a 1:1 line and the red solid line represents linear fit. DJF, the cold season.

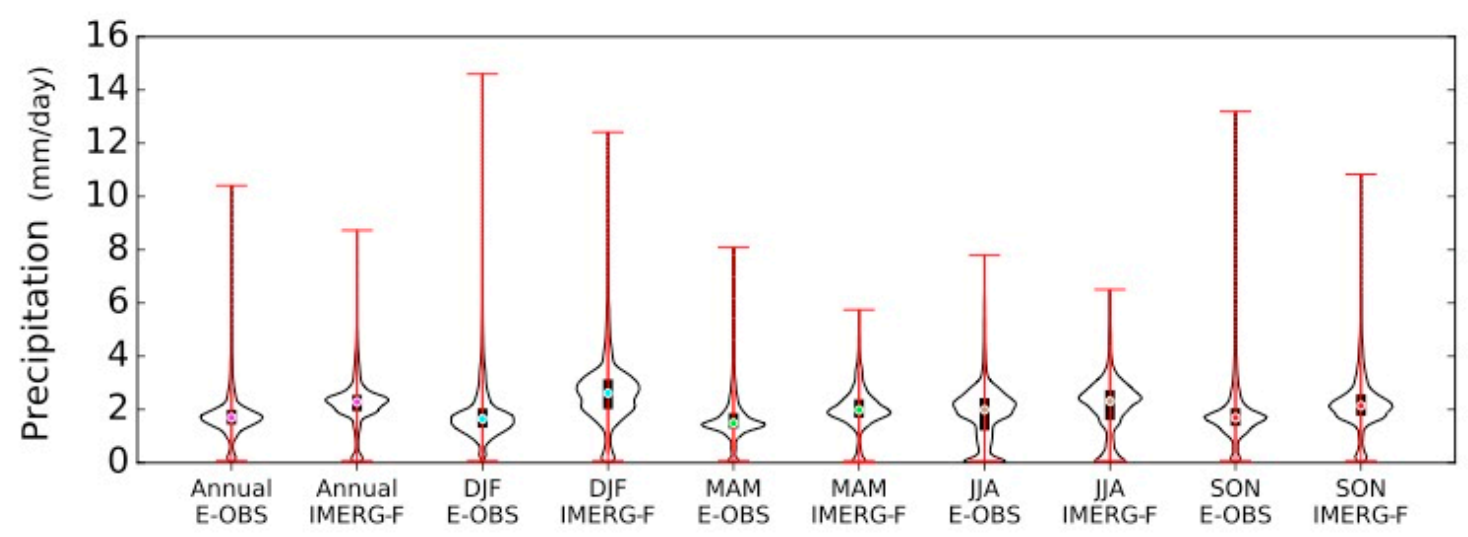

Figure 5. Probability density functions (PDFs) of annual and seasonal precipitation for E-OBS and IMERG-F.

\subsubsection{Monthly Time Series}

A further step in evaluating the performance of IMERG-F was the analysis of monthly data for 12 cities in Europe. Cities were selected to represent most climate regions of the continent. 
Figure 6 shows that IMERG-F correctly reproduced the time series of observations for 12 European cities. Indeed, it was able to capture severe events such as that reported in northern Italy during November 2014 [47]. Porto (POR), Amsterdam (AMS), and Paris (PAR) are examples of this good performance, but there are important discrepancies for Bergen (BER), Dublin (DUB), and Barcelona (BCN). The discrepancies for Bergen were in autumn-winter, but for Dublin they were over the entire period. Even with gauge calibration, PMW/IR sensors could not capture the actual precipitation signatures in those areas. Biases related to orographic lift and light rain detection might explain these problems. Barcelona is a very different case. It was affected by small number of events with high rainfall rates, which means that misrepresenting a single event could result in a poor monthly score [31].
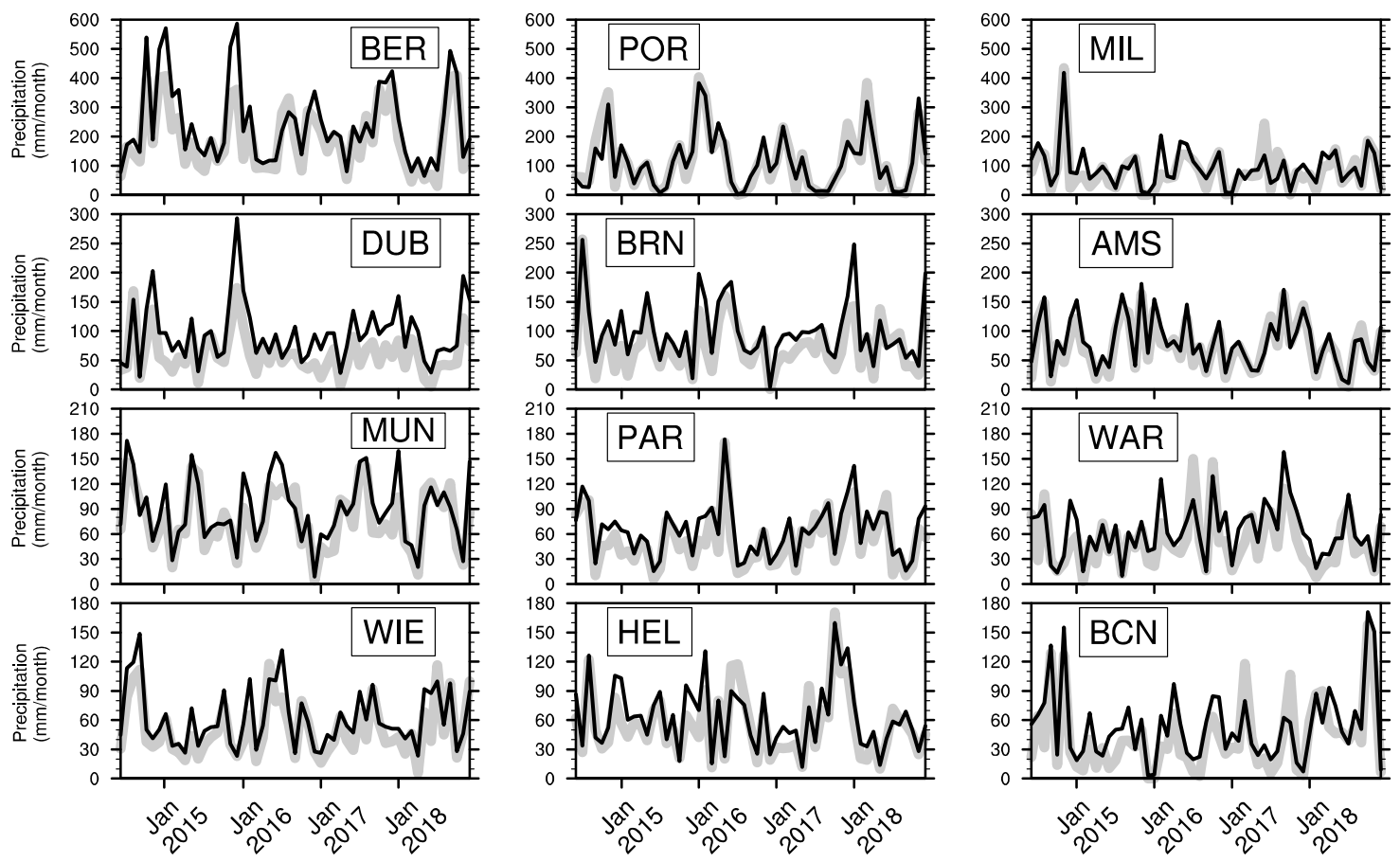

\section{E-OBS IMERG-F}

Figure 6. Time series of monthly precipitation for 12 European cities: Bergen (BER); Porto (POR); Milan (MIL); Dublin (DUB); Bern (BRN); Amsterdam (AMS); Munich (MUN); Paris (PAR); Warsaw (WAR); Vienna (WIE); Helsinki (HEL); Barcelona (BCN).

\subsection{IMERG Calibration}

The IMERG-F product incorporates actual rain gauge estimates from the GPCC based on the relative uncertainty of satellite data. Climatological calibration is important because satellite estimates are frequently biased because of indirect measurement. Thus, for instance, Guo et al. [48] found that the bias-correction procedure in IMERG-Cal greatly improved the quality relative to IMERG-Uncal regarding the spatial distribution of precipitation.

Figure 7 shows the normalized difference (left) and relative difference (right) between IMERG-Cal and IMERG-Uncal. It is clear from the figure that GPCC's calibration had an impact on IMERG-F. First, it reduced precipitation in central and northwestern France, on the Italian peninsula and Pannonian plain. Second, IMERG-Cal increased precipitation over mountainous areas, i.e., the Scandinavian Mountains, northwestern Scottish Highlands, Alps, and Cantabrian system of the northwestern Iberian Peninsula. After gauge calibration, IMERG-F showed favorable performance in those areas, but issues persisted when compared with E-OBS (cf. Figure 3). 


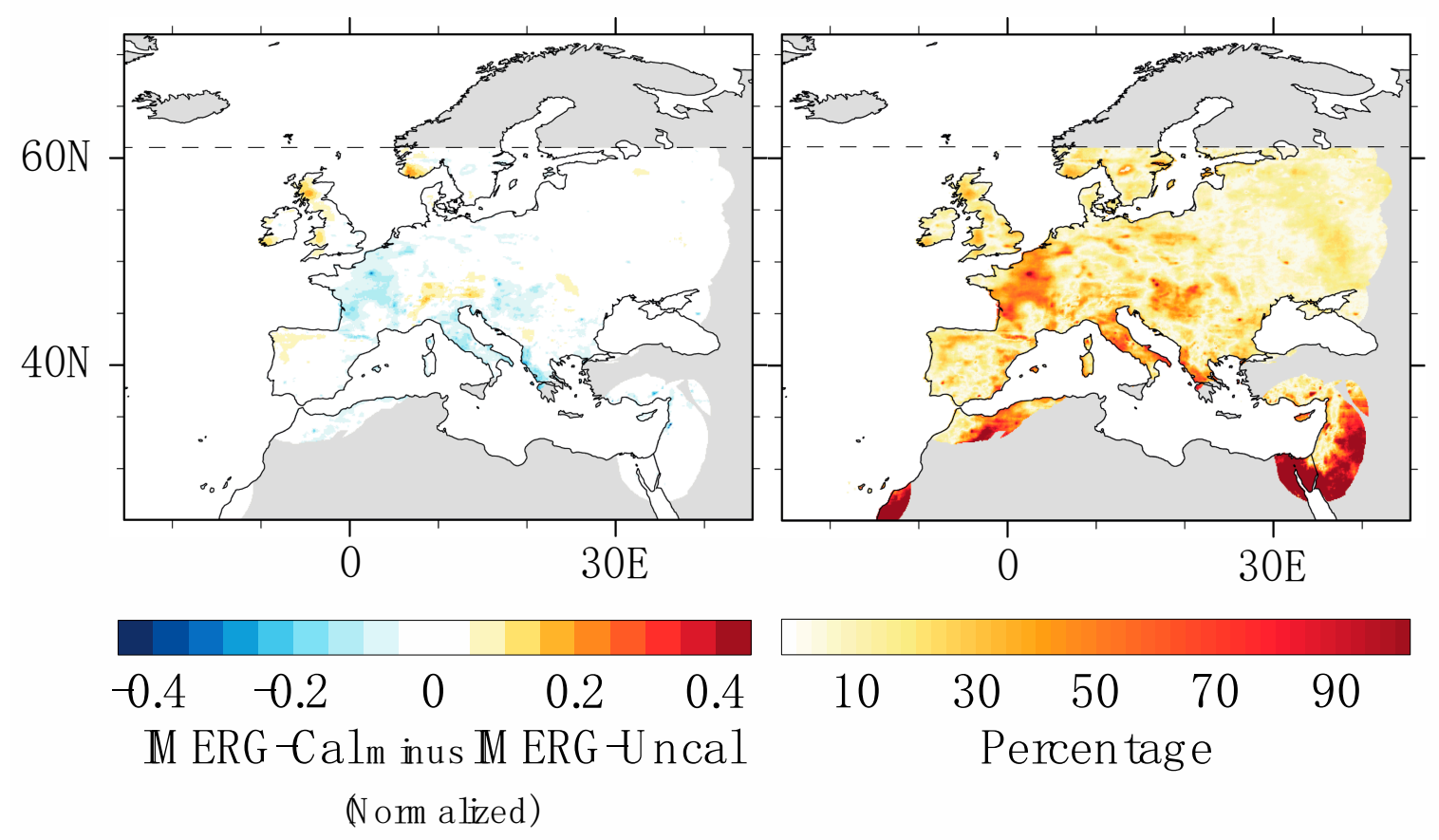

Figure 7. Normalized difference (left) and relative difference (right) between IMERG-Cal and IMERG-Uncal.

\subsection{Discrepancies between E-OBS and IMERG}

\subsubsection{Overview of Areas of Discrepancy}

The next test evaluated IMERG-F according to the number of rain gauges. Figure $8 \mathrm{~A}$ quantifies correlation between E-OBS and IMERG-F as a function of the number of rain gauges per pixel in the E-OBS dataset. The mean $\mathrm{R}^{2}$ correlation was nearly constant for all cases $(0.70)$, but correlation of the maxima substantially increased at pixels with more than three stations ( 0.90 with four gauges), and was nearly 0.99 at pixels with five or more gauges. This is not surprising because of two reasons, the minimizing effect of spatial interpolation and the increased number of shared stations between E-OBS and GPCC in those areas. 

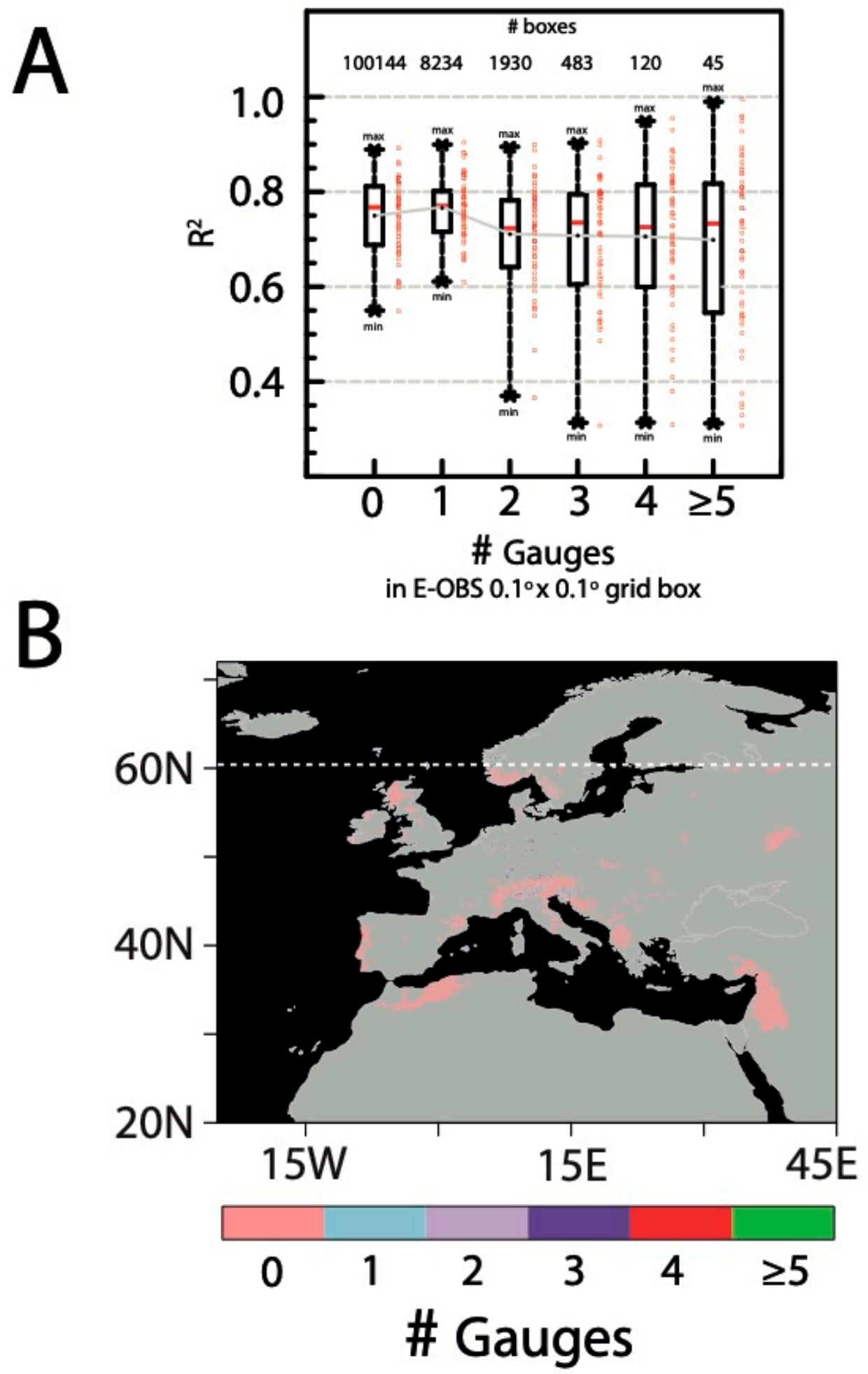

Figure 8. (A) Boxplots of correlation between E-OBS and IMERG-F monthly (June 2014-December 2018) estimates in each grid box, ordered according to the number of rain gauges in each box. (B) Map depicting the location of outlier pixels for which IMERG-F gave poor correlation according to the number of gauges.

The analysis of outlier pixels as defined by Cook's distance method is a means to identify areas where surface and satellite observations disagree. Figure $8 \mathrm{~B}$ shows which pixels were the largest contributors to poor performance according to the number of rain gauges available in E-OBS. 
As expected, most outliers were in areas where no gauges were available (pink pixels). Those were mountainous areas (Alps, the Dinarides, Pyrenees, and Scandinavian mountains) and coastal fringes (Adriatic coast and Atlantic coast of Portugal). Outlier pixels with one to two rain gauges were mostly in valleys surrounded by mountains and near coastlines (blue and light violet pixels). Pixels covered by three or more stations (dark violet, red, and green) were restricted to the central Alps, Slovenia, the Rhine, elevated areas in Germany such as the Harz and Thuringian forests, and the Calabria region of Italy. The next section provides a closer look at some of these regions.

Table 1 shows the correlation of monthly estimates according to five precipitation ranges. In general, the correlation increased when at least one rain gauge was available. The strongest correlation was in the range 0.1 to $<2.5 \mathrm{~mm} /$ day and $\geq 10.0 \mathrm{~mm} /$ day. Conversely, IMERG-F gave poor correlation in the driest areas $(<0.1 \mathrm{~mm} /$ day $)$ and in high elevations with precipitation between 5.0 and $<10.0 \mathrm{~mm} /$ day. A likely reason of the poor performance is the low number of quality gauges over these regions. That limits the calibration, and results in a suboptimal use of GPM data.

Table 1. Correlation $\left(\mathrm{R}^{2}\right)$ between EOBS and IMERG-F monthly estimates according to the rain gauges in each box and five rainfall categories ( $\mathrm{mm} /$ day).

\begin{tabular}{ccccccc}
\hline \multirow{2}{*}{ Precipitation (mm/day) } & \multicolumn{7}{c}{ Number of Gauges Per Pixel } \\
\cline { 2 - 7 } & $\mathbf{0}$ & $\mathbf{1}$ & $\mathbf{2}$ & $\mathbf{3}$ & $\mathbf{4}$ & $\mathbf{5}$ \\
\hline 0 to $<0.1$ & 0.05 & 0.04 & 0.03 & 0.1 & 0.05 & 0.35 \\
0.1 to $<2.5$ & 0.52 & 0.58 & 0.58 & 0.54 & 0.53 & 0.59 \\
2.5 to $<5.0$ & 0.20 & 0.24 & 0.22 & 0.22 & 0.19 & 0.27 \\
5.0 to $<10.0$ & 0.25 & 0.31 & 0.20 & 0.22 & 0.32 & 0.28 \\
$\geq 10.0$ & 0.43 & 0.44 & 0.32 & 0.55 & 0.67 & $*$ \\
\hline \multicolumn{7}{c}{ Not available. }
\end{tabular}

\subsubsection{Alps and Adriatic Sea}

Precipitation in complex terrain is a well-known issue in satellite-based products such as IMERG [49-51]. In mountainous regions, precipitation is extremely variable and there are changes in rainfall distribution over short distances. Additionally, higher altitudes mean that a large proportion of precipitation is in the solid phase, which is a challenge not only for satellites but also for rain gauges and weather radars [52]. A way to evaluate the performance of IMERG-F is by comparing it with the uncalibrated version of the product. Figure 9A compares annual mean precipitation over the Alps for E-OBS (second column) and the two versions of IMERG (IMERG-Cal and IMERG-Uncal). The uncalibrated version (fourth column) underestimated precipitation in that region, but IMERG-Cal partially reduced this problem (also seen in Figures 3 and 7). However, precipitation in the western Alps was still poorly represented. An explanation of this systematic bias is the difficulties of satellite sensors in identifying heavy orographic precipitation and problems in detecting light rain at high elevations $[50,53,54]$.

Another important region is the eastern coastline of the Adriatic Sea. Precipitation over this area is mainly caused by the advection of wet maritime air masses that interact with the Dinaric Alps, which precipitate windward of that mountain system. Figure 9B shows that IMERG-Cal yielded better results than the uncalibrated version. IMERG-Uncal produced heavier precipitation near the coastline with higher precipitation rates ( $>4.5 \mathrm{~mm} /$ day) beyond the Dinarides. Conversely, the calibrated product reduced this bias but still overestimated precipitation in the east $(\approx 2.2 \mathrm{~mm} /$ day). Measuring precipitation over coastal locations is an ongoing challenge reported by several authors $[31,55]$, and deserves further research. 
A
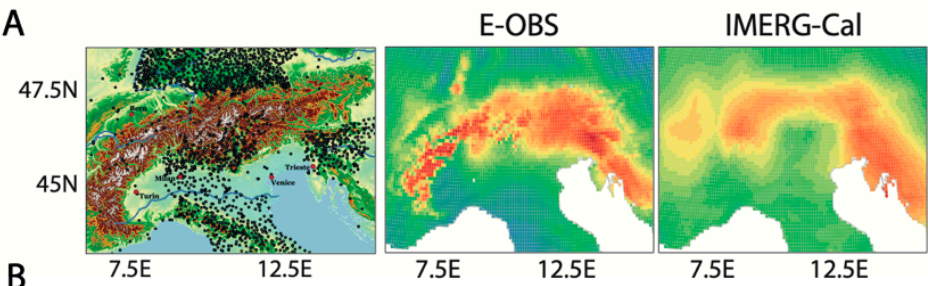

IMERG-Uncal IMERG comparison
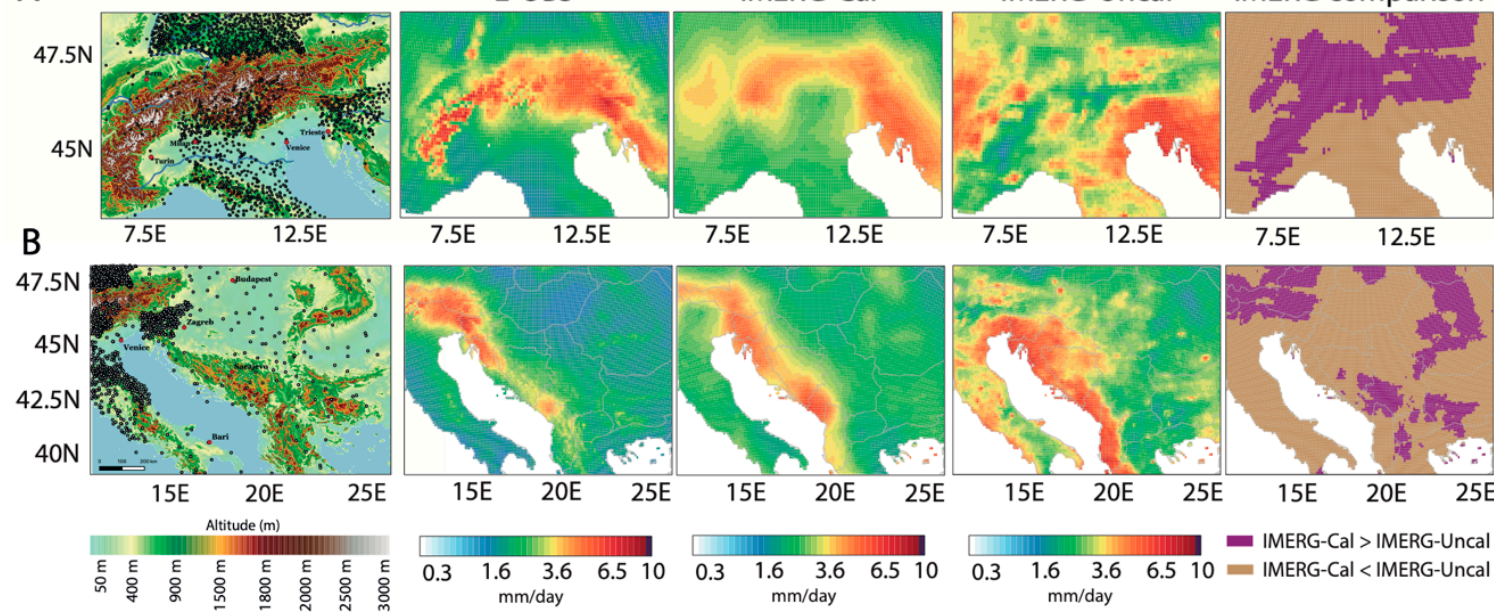

Figure 9. Annual mean precipitation comparison for the Alps (A) and Adriatic Sea (B) for June 2014-December 2018. First column shows topographic map of the area and rain gauge distribution. Second column shows annual mean precipitation for E-OBS, and the second (third) column IMERG calibrated (uncalibrated). The fourth column is a comparison of pixels where IMERG-Cal had more (less) precipitation than IMERG-Uncal. Units are $\mathrm{mm} /$ day.

\subsubsection{British Isles and Rhine}

Climatological calibration has important benefits for IMERG because it reduces biases in precipitation estimates. However, there are several areas where GPCC's gauge adjustment artificially smoothes spatial gradients of precipitation. Figure 10 shows two particular cases, namely, the High and Upper Rhine and the British Isles. The spatial gradient between the Vosges Mountains and Black Forest (Figure 10A) was better captured by IMERG-Uncal, although the calibrated version gave better precipitation estimates. The smoothing effect of gauge adjustment is clearer in Figure 10B, in which IMERG-Cal extended precipitation eastward on both islands.

A

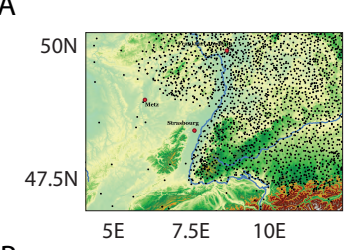

B

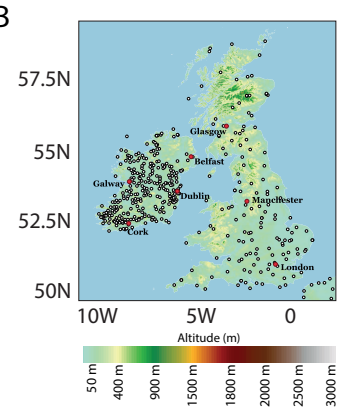

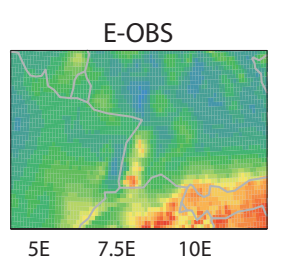

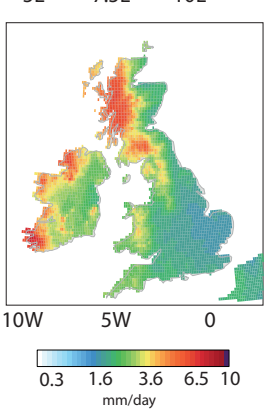

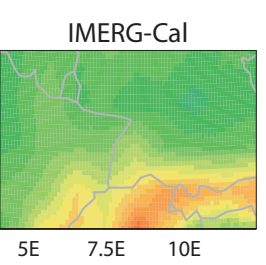

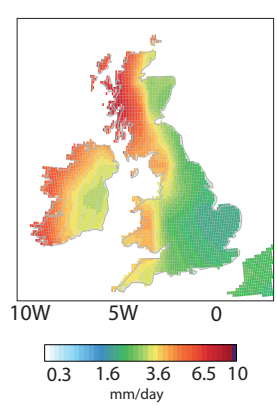

IMERG-Uncal
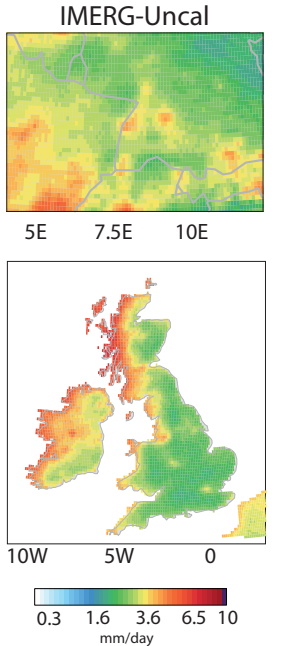
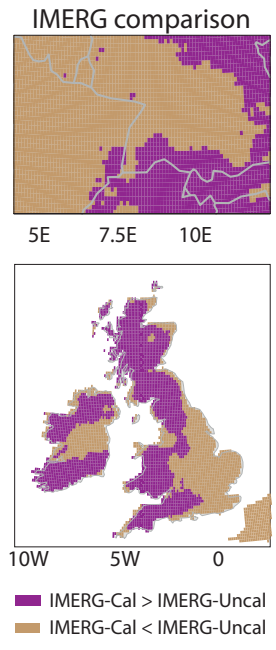

Figure 10. Annual mean precipitation comparison for High and Upper Rhine (A) and British Isles (B) for June 2014-December 2018. First column shows topographic map of the area and rain gauge distribution. Second column shows annual mean precipitation for E-OBS, and the second (third) column IMERG calibrated (uncalibrated). The fourth column is a comparison of pixels where IMERG-Cal had more (less) precipitation than IMERG-Uncal. Units are mm/day. 
To better understand the spatial variation of precipitation, it is necessary to use spatial statistics such as the variogram. This metric was first used by German and Joss (2000) to evaluate the spatial variation of Alpine precipitation. Figure 11 shows that the spatial pattern of fields of annual mean precipitation are very different. The E-OBS estimate quickly decorrelates and has sharper gradients (Figure 11 left). Interestingly, the uncalibrated version is closer to that pattern than IMERG-Cal. The main cause for this counterintuitive behavior is the smoothing effect of gauge adjustment. The poor spatial resolution of GPCC negatively affects IMERG-Cal, removing sharp gradients (also seen in Figure 10B). This problem is clearer in the British Isles (Figure 11 right) and is also present in other areas such as the Thuringian Forest and the Harz in Germany.
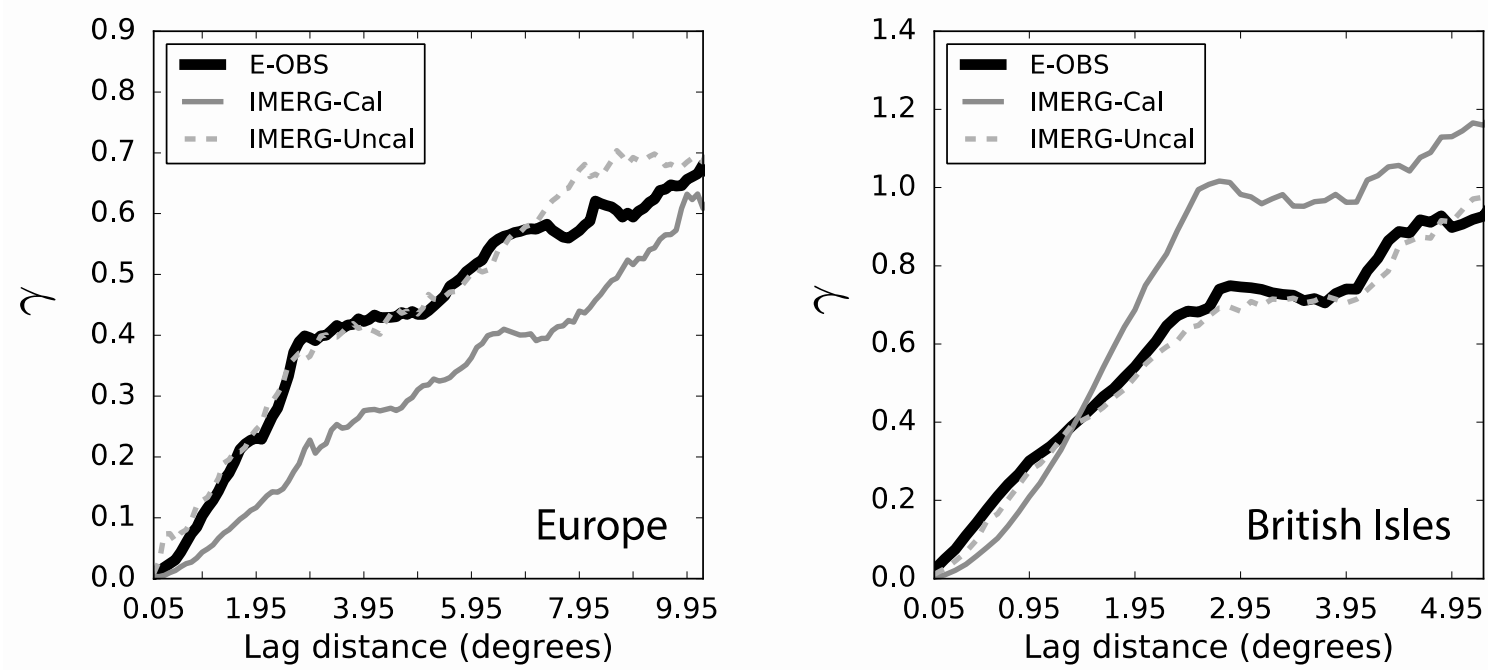

Figure 11. Variograms of annual mean precipitation (land-only) for Europe (Left) and British Isles

(right), showing E-OBS (black line), IMERG-Cal (gray line), and IMERG-Uncal (gray dotted line).

\subsubsection{Corsica}

Network density and location are also key elements for accurate rainfall estimates, especially in gridded products. Thus, as the resolution of a gridded dataset increases, the effects of rain gauge density also increase. This is critical in complex terrain areas where the number of rain gauges per pixel and their locations might produce different rainfall estimates [56].

Corsica is a French island in the Mediterranean Sea. Its typical Mediterranean landscape is modified by a longitudinal mountain range with the highest elevation above $2700 \mathrm{~m}$. Although most of the island has a Mediterranean climate (Csa and Csb), its center is dominated by a cold-summer Mediterranean climate (Csc) and temperate montane zones (Dfc and Dsc).

Figure 12A shows the spatial distribution of rain gauges over Corsica in the E-OBS dataset. The map illustrates that most gauges are at coastal locations (10 of 12 stations). Annual mean precipitation is greater than 1.7-1.8 mm/day in the coastal zones but fluctuates from 3.2 to $3.9 \mathrm{~mm} / \mathrm{day}$ in the high-elevation center of the island. A careful comparison between maps (Figure 12B) and precipitation records from Météo-France second-order rain gauges reveals that E-OBS underestimated precipitation in the center, which is a consequence of interpolation. For instance, Evisa, Bastelica, and Sampolo had 3.9, 3.5, and $3.2 \mathrm{~mm} /$ day, respectively. In those areas, IMERG-Uncal gave more realistic results than E-OBS. 
A

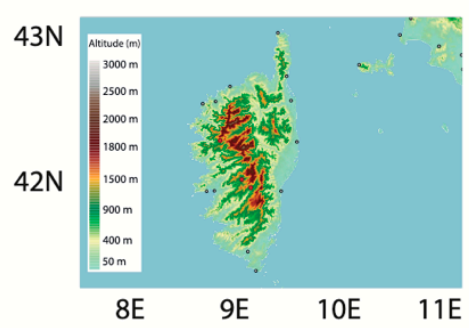

B

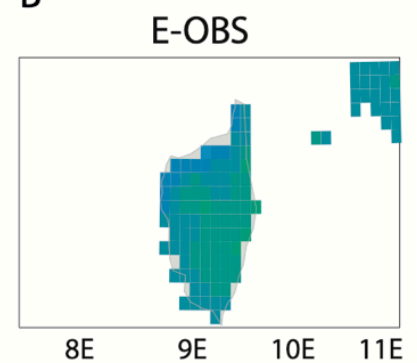

IMERG-Uncal

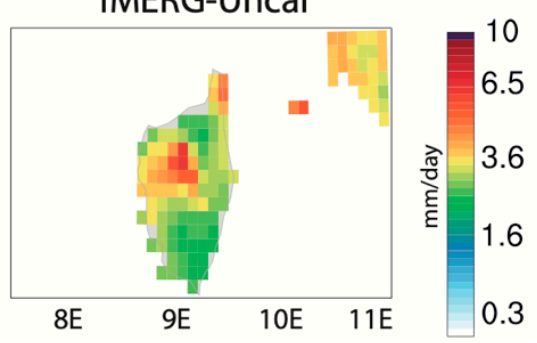

Figure 12. (A,B) Comparison of annual mean precipitation for E-OBS and IMERG-Uncal. First column shows topographic map of Corsica and the rain gauge distribution. White dots are E-OBS stations and red dots Météo-France stations. Second column shows annual mean precipitation for E-OBS and the third column that of IMERG-Uncal. Data from second-order stations are courtesy of Météo-France.

If the E-OBS dataset is biased toward lighter precipitation consistent with rain gauge density and location, a pertinent question regards the role of surface observations in complex terrain and/or gauge-poor areas. In such cases, IMERG-Uncal might produce a more reasonable representation of rainfall and gauge adjustment should be taken with caution. Indeed, considering the larger number of cases in which the satellite data compared well with an adequate number of gauges, it seems reasonable to use IMERG to fill the gaps in sparse rain gauge networks.

\section{Conclusions}

The IMERG "final run" (IMERG-F) accurately represented the precipitation climatology of Europe. It identified the rainiest areas and reproduced seasonal cycles correctly. However, there are several issues that should be addressed. First, IMERG-F underestimated precipitation in mountainous regions such as the Alps and Pyrenees. Even accounting for GPCC calibration, IMERG was unable to generate sufficient precipitation over these areas, which was caused by problems in the measurement of orographic precipitation from PMW. Second, the gauge adjustment negatively affected IMERG products in the High and Upper Rhine and British Isles because of the smoothing effect of the coarse resolution of GPCC. Third, the product had major problems in coastal areas with complex orography such as the coastline of the Adriatic Sea and northwestern Iberian Peninsula. This problem has been reported by several authors and the main cause might be algorithm limitations. Finally, there are some regions, e.g., Corsica, where discrepancies between IMERG and E-OBS were attributable to a scarcity of rain gauge stations, which produced large interpolation errors in gridded data [57]. In such cases, IMERG-Uncal offered a more realistic representation of the precipitation field.

E-OBS and IMERG-F are gridded precipitation datasets offering high-quality observational data over Europe at high spatial resolution $(10 \mathrm{~km})$, but neither are perfect. E-OBS interpolates over substantial distances and sometimes over complex areas. On the other hand, IMERG-F is an indirect measure that requires ground-based data to calibrate its outputs. Although the standard IMERG-F uses GPCC, a customized version of the product adjusted with the E-OBS dataset might provide a more realistic reproduction of the precipitation field over Europe. Future work should focus on exploiting the benefits of a dense rain gauge network such as E-OBS to improve IMERG products.

Author Contributions: A.N. led the research and drafted the manuscript. E.G.-O., A.M., J.L.S., C.K. and F.J.T. contributed to analysis and manuscript writing. F.J.T. led the project.

Funding: Funding came from projects LE240P18 (Consejería de Educación, Junta de Castilla y León) and CGL2013-48367-P, CGL2016-78702-C2-1-R and CGL2016-80609-R (Ministerio de Economía y Competitividad). Development of Numerical Weather Prediction and Data Application Technique 1365002970/KMA2018-00721 (Korean Meteorological Agency) is gratefully acknowledged.

Acknowledgments: We are in debt to Jean Dessens and Claude Berthet for data of Corsica.

Conflicts of Interest: The authors declare no conflict of interest. 


\section{References}

1. Tapiador, F.J.; Navarro, A.; Levizzani, V.; García-Ortega, E.; Huffman, G.J.; Kidd, C.; Kucera, P.A.; Kummerow, C.D.; Masunaga, H.; Petersen, W.A.; et al. Global precipitation measurements for validating climate models. Atmos. Res. 2017, 197, 1-20. [CrossRef]

2. Ricciardelli, E.; Di Paola, F.; Gentile, S.; Cersosimo, A.; Cimini, D.; Gallucci, D.; Geraldi, E.; Larosa, S.; Nilo, S.T.; Ripepi, E.; et al. Analysis of Livorno Heavy Rainfall Event: Examples of Satellite-Based Observation Techniques in Support of Numerical Weather Prediction. Remote Sens. 2018, 10, 1549. [CrossRef]

3. Lu, D.; Yong, B. Evaluation and Hydrological Utility of the Latest GPM IMERG V5 and GSMaP V7 Precipitation Products over the Tibetan Plateau. Remote Sens. 2018, 10, 2022. [CrossRef]

4. Tapiador, F.J.; Roca, R.; Del Genio, A.; Dewitte, B.; Petersen, W.; Zhang, F. Is Precipitation a Good Metric for Model Performance? Bull. Amer. Meteor. Soc. 2019, 100, 223-233. [CrossRef]

5. Michaelides, S.; Levizzani, V.; Anagnostou, E.; Bauer, P.; Kasparis, T.; Lane, J.E. Precipitation: Measurement, remote sensing, climatology and modeling. Atmos. Res. 2009, 94, 512-533. [CrossRef]

6. Michaelides, S. Editorial for Special Issue "Remote Sensing of Precipitation". Remote Sens. 2019, 11, 389. [CrossRef]

7. Kidd, C.; Becker, A.; Huffman, G.J.; Muller, C.L.; Joe, P.; Skofronick-Jackson, G.; Kirschbaum, D.B. So, how much of the Earth's surface is covered by rain gauges? Bull. Am. Meteorol. Soc. 2017, 98, 69-78. [CrossRef]

8. Michelson, D.B. Systematic correction of precipitation gauge observations using analyzed meteorological variables. J. Hydrol. 2004, 290, 161-177. [CrossRef]

9. Peterson, T.C.; Easterling, D.R.; Karl, T.R.; Groisman, P.; Nicholls, N.; Plummer, N.; Torok, S.; Auer, I.; Boehm, R.; Gullett, D.; et al. Homogeneity adjustments of in situ atmospheric climate data: A review. Int. J. Climatol. 1998, 18, 1493-1517. [CrossRef]

10. Kidd, C. Satellite rainfall climatology: A review. Int. J. Climatol. 2001, 21, 1041-1066. [CrossRef]

11. Sanò, P.; Panegrossi, G.; Casella, D.; Marra, A.C.; D’Adderio, L.P.; Rysman, J.F.; Dietrich, S. The Passive Microwave Neural Network Precipitation Retrieval (PNPR) Algorithm for the CONICAL Scanning Global Microwave Imager (GMI) Radiometer. Remote Sens. 2018, 10, 1122. [CrossRef]

12. Stampoulis, D.; Anagnostou, E.N. Evaluation of Global Satellite Rainfall Products over Continental Europe. J. Hydrometeorol. 2012, 13, 588-603. [CrossRef]

13. Kucera, P.A.; Ebert, E.E.; Turk, F.J.; Levizzani, V.; Kirschbaum, D.; Tapiador, F.J.; Loew, A.; Borsche, M. Precipitation from space: Advancing earth system science. Bull. Am. Meteorol. Soc. 2013, 94, 365-375. [CrossRef]

14. Hou, A.Y.; Kakar, R.K.; Neeck, S.; Azarbarzin, A.A.; Kummerow, C.D.; Kojima, M.; Oki, R.; Nakamura, K.; Iguchi, T. The global precipitation measurement mission. Bull. Am. Meteorol. Soc. 2014, 95, 701-722. [CrossRef]

15. Levizzani, V.; Bauer, P.; Turk, F.J. Measuring Precipitation from Space: EURAINSAT and the Future; Advances in Global Change Research; Springer: Dordrecht, The Netherlands, 2007; ISBN 978-1-4020-5834-9.

16. Sun, Q.; Miao, C.; Duan, Q.; Ashouri, H.; Sorooshian, S.; Hsu, K.-L. A Review of Global Precipitation Data Sets: Data Sources, Estimation, and Intercomparisons. Rev. Geophys. 2018, 56, 79-107. [CrossRef]

17. Huffman, G.J.; Bolvin, D.T.; Nelkin, E.J.; Wolff, D.B.; Adler, R.F.; Gu, G.; Hong, Y.; Bowman, K.P.; Stocker, E.F. The TRMM Multisatellite Precipitation Analysis (TMPA): Quasi-Global, Multiyear, Combined-Sensor Precipitation Estimates at Fine Scales. J. Hydrometeorol. 2007, 8, 38-55. [CrossRef]

18. Kubota, T.; Shige, S.; Hashizume, H.; Aonashi, K.; Takahashi, N.; Seto, S.; Hirose, M.; Takayabu, Y.N.; Ushio, T.; Nakagawa, K.; et al. Global Precipitation Map Using Satellite-Borne Microwave Radiometers by the GSMaP Project: Production and Validation. IEEE Trans. Geosci. Remote Sens. 2007, 45, 2259-2275. [CrossRef]

19. Huffman, G.J.; Bolvin, D.T.; Nelkin, E.J. Day 1 IMERG Final Run Release Notes; NASA: Washington, DC, USA, 2015; p. 9.

20. Skofronick-Jackson, G.; Kirschbaum, D.; Petersen, W.; Huffman, G.; Kidd, C.; Stocker, E.; Kakar, R. The Global Precipitation Measurement (GPM) mission's scientific achievements and societal contributions: Reviewing four years of advanced rain and snow observations. Q. J. R. Meteorol. Soc. 2018, 144, 27-48. [CrossRef]

21. Prakash, S.; Mitra, A.K.; Pai, D.S.; AghaKouchak, A. From TRMM to GPM: How well can heavy rainfall be detected from space? Adv. Water Resour. 2016, 88, 1-7. [CrossRef] 
22. Omranian, E.; Sharif, H.O.; Tavakoly, A.A. How well can Global Precipitation Measurement (GPM) capture hurricanes? Case study: Hurricane harvey. Remote Sens. 2018, 10, 1150. [CrossRef]

23. Khan, S.; Maggioni, V. Assessment of Level-3 Gridded Global Precipitation Mission (GPM) Products Over Oceans. Remote Sens. 2019, 11, 255. [CrossRef]

24. Wu, L.; Xu, Y.; Wang, S. Comparison of TMPA-3B42RT Legacy Product and the Equivalent IMERG Products over Mainland China. Remote Sens. 2018, 10, 1778. [CrossRef]

25. Mahmoud, M.T.; Al-Zahrani, M.A.; Sharif, H.O. Assessment of global precipitation measurement satellite products over Saudi Arabia. J. Hydrol. 2018, 559, 1-12. [CrossRef]

26. Rozante, J.R.; Vila, D.A.; Barboza Chiquetto, J.; Fernandes, A.D.A.; Souza Alvim, D. Evaluation of TRMM/GPM Blended Daily Products over Brazil. Remote Sens. 2018, 10, 882. [CrossRef]

27. Retalis, A.; Katsanos, D.; Tymvios, F.; Michaelides, S. Validation of the first years of GPM operation over Cyprus. Remote Sens. 2018, 10, 1520. [CrossRef]

28. Gaona, M.F.R.; Overeem, A.; Leijnse, H.; Uijlenhoet, R. First-Year Evaluation of GPM Rainfall over the Netherlands: IMERG Day 1 Final Run (V03D). J. Hydrometeorol. 2016, 17, 2799-2814. [CrossRef]

29. Ramsauer, T.; Weiß, T.; Marzahn, P. Comparison of the GPM IMERG Final Precipitation Product to RADOLAN Weather Radar Data over the Topographically and Climatically Diverse Germany. Remote Sens. 2018, 10, 2029. [CrossRef]

30. Sungmin, O.S.; Foelsche, U.; Kirchengast, G.; Fuchsberger, J.; Tan, J.; Petersen, W.A. Evaluation of GPM IMERG Early, Late, and Final rainfall estimates using WegenerNet gauge data in Southeastern Austria. Hydrol. Earth Syst. Sci. 2017, 21, 6559-6572.

31. Tapiador, F.J.; Navarro, A.; García-Ortega, E.; Merino, A.; Sánchez, J.L.; Kummerow, C.D. The Contribution of Rain Gauges in the Calibration of the GPM-IMERG Product. Results from the First Validation over Spain. J. Hydrometeorol. 2019, under review.

32. Tapiador, F.J.; Moreno, R.; Navarro, A.; Sánchez, J.L.; García-Ortega, E. Climate classifications from regional and global climate models: Performaces for present climate estimates and expected changes in the future at high spatial resolution. Atmos. Res. 2019, 228, 107-121. [CrossRef]

33. Köppen, W. Versuch einer Klassifikation der Klimate, vorzugsweise nach ihren Beziehungen zur Pflanzenwelt. Geogr. Zeitschrift 1900, 6, 657-679.

34. Cornes, R.C.; van der Schrier, G.; van den Besselaar, E.J.M.; Jones, P.D. An Ensemble Version of the E-OBS Temperature and Precipitation Data Sets. J. Geophys. Res. Atmos. 2018, 123, 9391-9409. [CrossRef]

35. Haylock, M.R.; Hofstra, N.; Tank, A.M.G.K.; Klok, E.J.; Jones, P.D.; New, M. A European daily high-resolution gridded data set of surface temperature and precipitation for 1950-2006. J. Geophys. Res. Atmos. 2008, 113. [CrossRef]

36. Klok, E.J.; Tank, A.M.G.K. Updated and extended European dataset of daily climate observations. Int. J. Climatol. 2009, 29, 1182-1191. [CrossRef]

37. Hofstra, N.; Haylock, M.; New, M.; Jones, P.D. Testing E-OBS European high-resolution gridded data set of daily precipitation and surface temperature. J. Geophys. Res. Atmos. 2009, 114. [CrossRef]

38. Kotlarski, S.; Keuler, K.; Christensen, O.B.; Colette, A.; Déqué, M.; Gobiet, A.; Goergen, K.; Jacob, D.; Lüthi, D.; Van Meijgaard, E.; et al. Regional climate modeling on European scales: A joint standard evaluation of the EURO-CORDEX RCM ensemble. Geosci. Model Dev. 2014, 7, 1297-1333. [CrossRef]

39. Spinoni, J.; Naumann, G.; Vogt, J.V.; Barbosa, P. The biggest drought events in Europe from 1950 to 2012. J. Hydrol. Reg. Stud. 2015, 3, 509-524. [CrossRef]

40. Caroletti, G.N.; Coscarelli, R.; Caloiero, T. Validation of Satellite, Reanalysis and RCM Data of Monthly Rainfall in Calabria (Southern Italy). Remote Sens. 2019, 11, 1625. [CrossRef]

41. Nastos, P.T.; Kapsomenakis, J.; Douvis, K.C. Analysis of precipitation extremes based on satellite and high-resolution gridded data set over Mediterranean basin. Atmos. Res. 2013, 131, 46-59. [CrossRef]

42. Retalis, A.; Katsanos, D.; Michaelides, S. Precipitation climatology over the Mediterranean Basin-Validation over Cyprus. Atmos. Res. 2016, 169, 449-458. [CrossRef]

43. Schneider, U.; Finger, P.; Meyer-Christoffer, A.; Rustemeier, E.; Ziese, M.; Becker, A. Evaluating the Hydrological Cycle over Land Using the Newly-Corrected Precipitation Climatology from the Global Precipitation Climatology Centre (GPCC). Atmosphere 2017, 8, 52. [CrossRef] 
44. Huffman, G.J.; Bolvin, D.; Braithwaite, D.; Hsu, K.-L.; Joyce, R.; Kidd, C.; Nelkin, E.; Sorooshian, S.; Tan, J.; Xie, P. Integrated Multi-Satellite Retrievals for GPM (IMERG) Technical Documentation; NASA/GSFC: Greenbelt, MD, USA, 2018.

45. Kummerow, C.D. GPROF2017 Version 1; NASA/GSFC: Greenbelt, MD, USA, 2017.

46. Cook, R.D.; Weisberg, S. Residuals and Influence in Regression; Chapman and Hall: New York, NY, USA, 1982.

47. Copernicus Emergency Management Service. EMSR108: Landslides and Floods in Northern Italy; European Commission Joint Research Centre: Brussels, Belgium, 2014.

48. Guo, H.; Chen, S.; Bao, A.; Behrangi, A.; Hong, Y.; Ndayisaba, F.; Hu, J.; Stepanian, P.M. Early assessment of Integrated Multi-satellite Retrievals for Global Precipitation Measurement over China. Atmos. Res. 2016, 176, 121-133. [CrossRef]

49. Houze, R.A. Orographic effects on precipitating clouds. Rev. Geophys. 2012, 50. [CrossRef]

50. Maggioni, V.; Nikolopoulos, E.I.; Anagnostou, E.N.; Borga, M. Modeling Satellite Precipitation Errors Over Mountainous Terrain: The Influence of Gauge Density, Seasonality, and Temporal Resolution. IEEE Trans. Geosci. Remote Sens. 2017, 55, 4130-4140. [CrossRef]

51. Krakauer, N.Y.; Pradhanang, S.M.; Lakhankar, T.; Jha, A.K. Evaluating Satellite Products for Precipitation Estimation in Mountain Regions: A Case Study for Nepal. Remote Sens. 2013, 5, 4107-4123. [CrossRef]

52. Wen, Y.; Behrangi, A.; Lambrigtsen, B.; Kirstetter, P.-E. Evaluation and uncertainty estimation of the latest radar and satellite snowfall products using SNOTEL measurements over mountainous regions in western United States. Remote Sens. 2016, 8, 904. [CrossRef]

53. Hirpa, F.A.; Gebremichael, M.; Hopson, T. Evaluation of High-Resolution Satellite Precipitation Products over Very Complex Terrain in Ethiopia. J. Appl. Meteor. Climatol. 2009, 49, 1044-1051. [CrossRef]

54. Gabella, M.; Speirs, P.; Hamann, U.; Germann, U.; Berne, A. Measurement of precipitation in the Alps using dual-polarization C-Band ground-based radars, the GPMSpaceborne Ku-Band Radar, and rain gauges. Remote Sens. 2017, 9, 1147. [CrossRef]

55. Asong, Z.E.; Razavi, S.; Wheater, H.S.; Wong, J.S. Evaluation of Integrated Multisatellite Retrievals for GPM (IMERG) over Southern Canada against Ground Precipitation Observations: A Preliminary Assessment. J. Hydrometeorol. 2017, 18, 1033-1050. [CrossRef]

56. Herrera, S.; Kotlarski, S.; Soares, P.M.M.; Cardoso, R.M.; Jaczewski, A.; Gutiérrez, J.M.; Maraun, D. Uncertainty in gridded precipitation products: Influence of station density, interpolation method and grid resolution. Int. J. Climatol. 2019, 39, 3717-3729. [CrossRef]

57. Hofstra, N.; New, M.; McSweeney, C. The influence of interpolation and station network density on the distributions and trends of climate variables in gridded daily data. Climate Dyn. 2010, 35, 841-858. [CrossRef] 